\title{
The potential neuroprotective effects of weekly treatment with glatiramer acetate in diabetic patients after panretinal photocoagulation
}

This article was published in the following Dove Press journal:

Clinical Ophthalmology

14 July 201 I

Number of times this article has been viewed

\author{
Somaia Mitne ${ }^{1,2}$ \\ Sergio Henrique Teixeira' \\ Michal Schwartz ${ }^{3}$ \\ Michael Belkin ${ }^{4}$ \\ Michel Eid Farah' \\ Nilva S Bueno de Moraes' \\ Luciana da Cruz Nóia' \\ Ângela Tavares Paes ${ }^{2}$ \\ Cláudio Luiz Lottenberg ${ }^{2}$ \\ Augusto Paranhos Júnior ${ }^{1,2}$ \\ 'Department of Ophthalmology, \\ Federal University of São Paulo, \\ 2Instituto Israelita de Ensino e \\ Pesquisa Albert Einstein, HIAE, \\ São Paulo, Brazil; ${ }^{3}$ Department of \\ Neurobiology, The Weizmann Institute \\ of Science, Rehovot, ${ }^{4}$ Goldschleger \\ Eye Research Institute, Tel-Aviv \\ University, Sheba Medical Center, \\ Tel HaShomer, Israel
}

Purpose: Evaluation of the neuroprotective effect of weekly glatiramer acetate (GA) on retinal structure and function in diabetic patients who underwent panretinal photocoagulation (PRP). Patients and methods: Patients with severe nonproliferative or early proliferative diabetic retinopathy and no previous laser treatment were randomly divided into two groups: (1) those who received four GA treatments and (2) those who received placebo treatment. The subcutaneous injections were administered 1 week prior to laser and weekly in the subsequent three sessions of PRP in both groups. All patients underwent a full ophthalmic examination (best-corrected $\log$ MAR visual acuity, slit lamp examination, applanation tonometry, fundus biomicroscopy and indirect fundus examination); functional examination (standard automated perimetry, electroretinography and frequency-doubling technology C-20 visual field) and anatomic examination (color photography, optical coherence tomography (OCT) and Heidelberg retinal tomography). The examinations were performed before the photocoagulation and repeated 1,3,6, and 12 months after treatment (in a double-masked manner). To compare the two groups, generalized estimating equation models were performed to account for the dependence between eyes of the same patient.

Results: Thirteen patients ( 23 eyes) were included in the study group and 13 patients ( 24 eyes) were included in the control group. OCT showed a statistically significant difference in retinal nerve fiber layer (RNFL) thickness in the inferior peripapillary region and average thickness with thinner measurements in the control group at 1-year post-PRP. Functional analysis demonstrated a difference between groups, but it did not reach statistical significance.

Conclusion: The results of this study suggest that weekly GA treatment has a potential neuroprotective effect on the RNFL following photocoagulation for diabetic retinopathy.

Keywords: diabetic retinopathy, panretinal photocoagulation, glatiramer acetate, neuroprotection

\section{Introduction}

Diabetic retinopathy is a leading cause of severe loss of visual acuity despite an increased understanding of this disease and the identification of successful treatments. ${ }^{1}$ The Diabetic Retinopathy Study showed the benefits of panretinal photocoagulation (PRP) in reducing the risk of severe visual loss by $>50 \%$ in eyes with high-risk characteristics. ${ }^{2}$ The Early Treatment Diabetic Retinopathy Study (ETDRS) confirmed that PRP should also be performed in eyes with severe nonproliferative and non-high-risk proliferative diabetic retinopathy. ${ }^{3,4}$ Furthermore, ETDRS ${ }^{5}$ defined the indications of laser treatment in clinically significant macular edema. However, retinal photocoagulation may lead to complications and retinal damage. After primary laser injury, the local lesions may spread and lead to an increased morphological and functional damage. ${ }^{6-8}$
Correspondence: Somaia Mitne

Rua Embuaçu, I79 ap. I3I, Vila Mariana,

São Paulo, Brazil 04| I8-080

Tel +55 II 97633094

Fax +55 || 507 I8888

Email somitne@gmail.com 
Therefore, we hypothesized that combining laser therapy with neuroprotection may improve the outcome of this intervention: neuroprotection aims to prevent the spread of damage resulting from mechanical or biochemical damage. ${ }^{9-13}$ The neuroprotective action of weekly glatiramer acetate (GA) has been demonstrated in models of neuronal damage caused by elevated intraocular pressure and intraocular glutamate toxicity ${ }^{11-14}$ as well as in chronic neurodegenerative conditions such as an animal model of Alzheimer's disease. ${ }^{15}$ This study was conducted to evaluate the outcome of retinal anatomy and function in diabetic patients following panretinal photocoagulation, using immune-based neuroprotection therapy with weekly administered GA.

\section{Material and methods}

In this randomized, controlled clinical trial, we enroled diabetic insulin-dependent and noninsulin-dependent patients with very severe nonproliferative or early proliferative retinopathy from the Retina Sector of the Federal University of São Paulo (UNIFESP) between July 2006 and July 2007. The protocol was approved by the Research Ethics Committee of the Federal University of São Paulo. Informed consent was obtained from all participants in accordance with the tenets of the 1989 Declaration of Helsinki. Patients, ophthalmologists, technical staff and statisticians participated in a masked fashion. The study was conducted using scientific methodology based on the Revised CONSORT ${ }^{16}$ statement for randomized trials. Clinical trial identifier (http://www. ClinicalTrials.gov): NCT00677664.

\section{Patient enrolment and baseline evaluation}

Patients were included if they had: type 1 or 2 diabetes, been recommended for panretinal photocoagulation; vision acuity of 20/100 or better; spherical equivalent of \pm 6.00 spherical diopters. Exclusion criteria related to the eye were: previous retinal photocoagulation or cryopexy of any kind; dense cataract or vitreous opacity; retinal disease other than diabetic retinopathy; ocular hypertension or glaucoma (IOP higher than $21 \mathrm{mmHg}$ and/or cup disk ratio equal to or higher than 0.8 ) or other optic nerve diseases; and ocular surgery within the last 6 months, including laser treatment. Systemic exclusion criteria were: known immunological condition/disease; active infection within 30 days prior to enrolment (eg, urinary tract infection, upper/lower respiratory tract infection, skin infection, arthritis); use of interferon or immunosuppressive, cytotoxic or corticosteroid chemotherapy or lymphoid irradiation within 1 year prior to study entry; serious disease in the past or an unstable disease such as cancer, pulmonary, hepatic, renal, cardiovascular or metabolic diseases; being a volunteer who participated in another clinical trial within the past 90 days or took an experimental drug within a time scale of $5 \times \mathrm{t}_{1 / 2}$ of the experimental drug; and unstable psychiatric illness.

All patients were subjected to a series of tests. A full ophthalmic examination included best-corrected logarithm of minimal angle of resolution (logMAR) visual acuity (BCVA) as measured with ETDRS charts, applanation tonometry, undilated and dilated slit-lamp biomicroscopic examination, and indirect fundus examination. A functional examination included Humphrey 30-2 SITA STANDARD visual field (Humphrey Field Analyzer, II-750; Carl Zeiss Meditec, Dublin, CA), electroretinography full-field (ERG, UTAS E-3000; LKC Technologies Inc, Gaithersburg, MD) according to the standard protocol recommended by the International Society for Clinical Electrophysiology of Vision (ISCEV) and frequency-doubling technology C-20 visual field (FDT Matrix; Carl Zeiss Meditec). A morphological examination included: colour fundus photography and fluorescein angiography (FA), using a Heidelberg retina angiograph, (Heidelberg Engineering, Dossenheim, Germany) in cases of clinically significant macular edema; these examinations were done in order to guide the focal laser treatment. Optical coherence tomography (Stratus OCT3; Carl Zeiss Meditech) was performed to measure the retinal nerve fiber layer (RNFL) thickness around the optic disk and macular area, and Heidelberg retinal tomography (HRT, Heidelberg Instruments $\mathrm{GmbH}$, Heidelberg, Germany) was performed to measure the optic disk rim area as well as the cup disk and rim area.

\section{Treatment assignment}

Patients were divided in two groups using a computergenerated random table. Numbered opaque envelopes contained the type of intervention: GA (GA group) or placebo (control group). All data from patients' examinations were analyzed within the group to which they were originally assigned. All patients were treated with laser photocoagulation consisting of full-scatter PRP treatment performed during three sessions (at weeks 1, 2, and 3) according to the ETDRS guidelines. Four to six hundred 250- $\mu \mathrm{m}$ spots were performed per PRP episode at the discretion of the same treating investigator (S Mitne); these spots were sequentially performed in each eye on the same day. Macular (focal or grid) laser photocoagulation guided by FA was also performed in cases with clinically significant 
macular edema at the first laser treatment session (week 1) and was repeated after 3 months in cases of persistent macular edema. The GA group received injections containing $20 \mathrm{mg}$ of glatiramer acetate (also known as Cop-1, Copolymer-1, Copaxone ${ }^{\mathrm{TM}}$; Teva Pharmaceutical Industries Ltd, Kfar-Saba, Israel). The control group received just the vehicle: mannitol injections. All injections of either GA or the vehicle only were done subcutaneously 1 week prior to the first PRP session and then weekly immediately before the three subsequent PRP sessions.

\section{Follow-up examinations and outcome measures}

Patients were followed up at 1, 3, 6, and 12 months after the completion of the treatment procedures. At these visits, they underwent a complete ophthalmic examination including the same procedures that were performed at baseline.

\section{Statistical analysis}

The sample size calculation was based on previously published data ${ }^{17}$ in which patients who did not undergo laser treatment presented a mean RNFL thickness of $135.8 \mu \mathrm{m}$ in the inferior region and a standard deviation of $29.8 \mu \mathrm{m}$. Assuming a control group loss of $20 \%$ after laser treatment vs $1 \%$ for the GA group, a sample size of 15 patients per group would be necessary to reach a power of $80 \%$ and a significance level of $5 \%$.

Upon baseline evaluation, the chi-square or Fisher's exact test was used for categorical variables (sex, race, retinopathy grade) and Student's $t$-test or the Mann-Whitney test was used for numeric variables (age, duration of diabetes and glycemia). To compare both groups regarding anatomical and functional examinations generalized estimating equation $(\mathrm{GEE})^{18,19}$ models were performed to account for the dependence between eyes of the same patient. SPSS (v 17.0 for Windows; SPSS, Inc, Chicago, IL) was used for statistical analysis.

\section{Results}

Forty-seven eyes from 26 diabetic patients with very severe nonproliferative or proliferative retinopathy were included in this study. All patients were treated with PRP. Thirteen patients (23 eyes) were included in the GA group and thirteen patients (24 eyes) were included in the control group. All patients with clinically significant macular edema were treated with macular laser: 15 eyes in the GA group and 18 eyes in the control group, with no statistically significant difference between groups ( $P=0.32$, chi-squared test adjusted for inter-eye dependency). Demographic data and baseline characteristics are summarized in Table 1.

Figure 1 shows the participants throughout each stage of the study. After enrolment, one patient was excluded due to diabetic optic neuropathy. In the allocation phase (prior to the treatment), one eye from the GA group and two eyes from the control group showed vitreous hemorrhage; therefore, laser treatment could not be completed. One patient (one eye) from the control group abandoned the study before completing the treatment. Another patient (one eye) from the control group was dropped from the follow-up due to an orthopedic disease 3 months after treatment. During analysis, all exclusions were performed with

Table I Demographic data and baseline characteristics of patients treated with glatiramer acetate (GA group) and placebo (control group)

\begin{tabular}{llll}
\hline & GA group & Control group & Mean difference (CI 95\%) \\
\hline $\begin{array}{l}\text { Age (years), mean (SD) } \\
\text { Gender, n (\%) }\end{array}$ & $54.4(7.9)$ & $54.9(11.8)$ & $0.54(-7.56 ; 8.64)$ \\
$\quad$ Male & $5(38.5 \%)$ & $8(61.5 \%)$ & $23.1 \%(-14.3 ; 60.5)$ \\
$\quad$ Female & $8(61.5 \%)$ & $5(38.5 \%)$ & \\
Race, n (\%) & & & \\
$\quad$ Asian & $1(7.7 \%)$ & $10 \%)$ & $-7.7 \%(-37.8 ; 22.5)$ \\
White & $9(69.2 \%)$ & $2(15.4 \%)$ & $-1.69(-6.29 ; 2.91)$ \\
$\quad$ Black & $3(23.1 \%)$ & $13.1(4.3)$ & $-15.4 \%(-50.4 ; 19.6)$ \\
T_DM (years), mean (SD) & $14.8(6.8)$ & $8(61.5 \%)$ & $38.5 \%(3.5 ; 73.4)$ \\
PDR n (\%) & $10(76.9 \%)$ & $8(61.5 \%)$ & $22.5^{\mathrm{a}}$ \\
Insulin n (\%) & $3(23.1 \%)$ & $195.0(150.0-232.0)$ & $-33.5^{\mathrm{a}}$ \\
Gli_I, median (IQR) & $172.5(I 55.0-220.0)$ & $150.0(133.0-160.0)$ & \\
Gli_6M, median (IQR) & $183.5(160.5-263.0)$ & &
\end{tabular}

Note: anedian difference.

Abbreviations: GA group, treated with glatiramer acetate; SD, standard deviation; Cl, confidence interval; IQR, interquartile range; T_DM, duration of diabetes; PDR, proliferative diabetic retinopathy; Gli_I, baseline fasting blood glucose; Gli_6M, 6-month fasting blood glucose. 


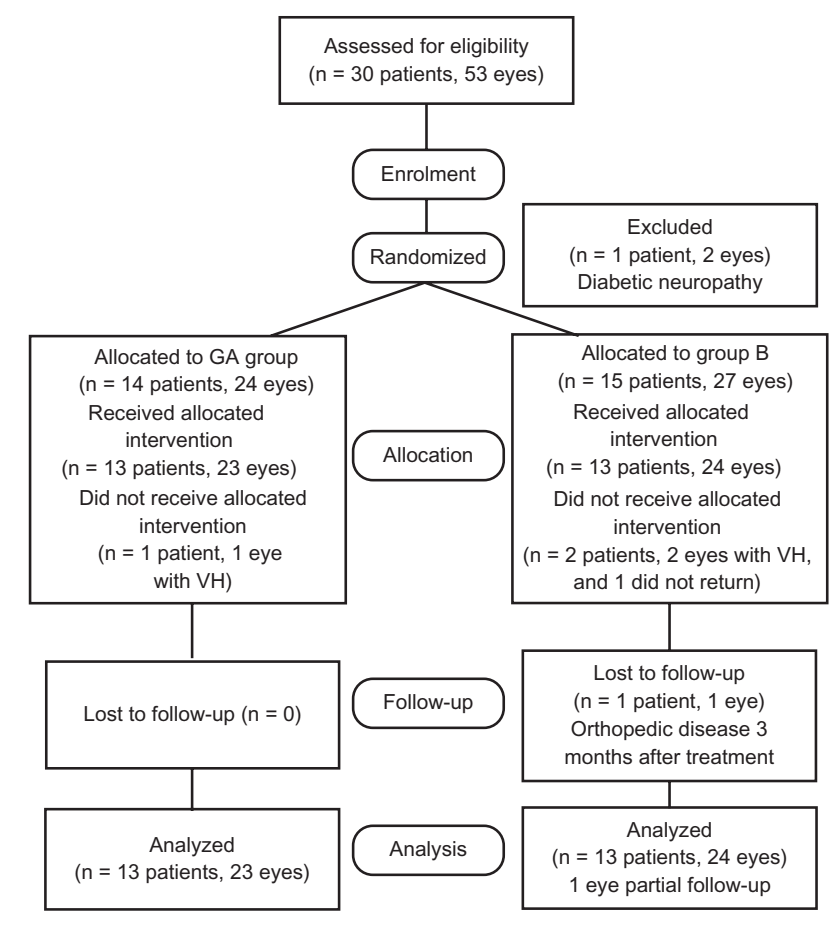

Figure I Diagram showing the flow of participants through each stage of the randomized trial.

Abbreviation: $\mathrm{VH}$, vitreous hemorrhage.

the investigators still masked for anatomical and functional evaluation. Partial data for three patients in each group were excluded from the main outcome analysis due to vitreous hemorrhage (three eyes in the GA group), partial retinal detachment (two eyes in the control group), submacular hemorrhage (one eye in the control group), and HRT with low reliability (one eye in the GA group and two eyes in the control group). The exclusions were limited to the period during which the event occurred (for each patient, if one or more examinations were excluded due to quality, future examinations from the same patient could enter in the analyses, if the quality was appropriate.) Table 2 shows the comparison between both groups regarding all anatomical and functional evaluation data.

\section{Within group analysis}

A statistically significant difference in RNFL thickness was detected in the inferior peripapillary region and in the average thickness measurements assessed by OCT in the control group when comparing preoperative values to those obtained at 12 month follow-up. The control group had an initial mean $( \pm$ SE) inferior RNFL thickness of $143.98 \mu \mathrm{m} \pm 4.62 \mu \mathrm{m}$ and an average thickness of $119.84 \mu \mathrm{m} \pm 5.82 \mu \mathrm{m}$, and these became significantly thinner at 1 year post-PRP: $132.01 \mu \mathrm{m} \pm 6.30 \mu \mathrm{m}$ and $110.07 \mu \mathrm{m} \pm 5.09 \mu \mathrm{m}$, respectively.

\section{Between group analysis}

Figure 2 shows less RNFL atrophy, less visual field mean deviation (VFMD) worsening and less B-wave reduction in the GA group although these differences were not statistically significant. The mean logMAR BCVA in the group treated with GA was 0.362 compared with 0.598 in the placebo group at 6 months. The difference reached significance, but it was not sustained when the analysis was performed with macular thickness as a covariable (Table 2). Macular thickness was significantly different between groups; it was higher in the control group in all examinations. We found no statistically significant difference between groups regarding HRT or FDT (data not shown).

No drug-related adverse events were observed in any patients treated with GA or placebo.

\section{Discussion}

Laser photocoagulation, which is the common treatment of choice for diabetes, has a negative impact on retinal ganglion cell survival, leading to the significant progression of morphological and functional damage.$^{6-8}$ Rescue of such retinal ganglion cells could be achieved, in principle, by neuroprotection..$^{9,10,14}$ Here we present a pilot study disclosing a potential beneficial effect of neuroprotective vaccination in these patients.

Neuroprotective immunization is based on the concept of "protective autoimmunity" formulated by Schwartz's group,${ }^{20}$ who showed that a $\mathrm{T}$ cell-mediated immune response is neuroprotective after injury and that its effect can be boosted by either passive or active immunization. ${ }^{11,12,21,22}$ It has been demonstrated that adoptive transfer of $\mathrm{T}$ cells specific for proteins associated with CNS myelin, such as myelin basic protein, reduces the post-traumatic secondary degeneration of the rat optic nerve and spinal cord. ${ }^{20}$ It was found that $\mathrm{T}$ cells, upon recognizing their antigen, secrete growth factors and facilitate recruitment of blood monocytes that locally display a regulatory role that helps restore homeostasis in nervous system maintenance. ${ }^{23,24}$ Immune response boosting can be achieved by immunization with peptides derived from relevant autoantigens, or by synthetic antigens, such as GA, that weakly cross-react with self-antigens. ${ }^{12}$ Such neuroprotection increases the ability of the damaged tissue to cope with the neurotoxicity and thereby to arrest the spread of laser damage.

Belokopytov et al used electroretinography to demonstrate the neuroprotective effect of GA treatment for retinal laser burns in rats. ${ }^{25}$ This was the first report of neuroprotection of nonmyelinated neurons. A similar laser injury model was 
Table 2 Evaluation of mean differences for anatomical and functional parameters (between and within comparisons considered, adjusted for repeated measurements)

\begin{tabular}{|c|c|c|c|c|}
\hline Parameter & Period & GA group $(n=13)$ & Control group $(n=13)$ & Mean difference ( $\mathrm{Cl} 95 \%)$ \\
\hline \multicolumn{5}{|c|}{ Functional parameters } \\
\hline \multirow[t]{3}{*}{ BCVA (logMAR) } & Pre & $0.398(0.077)$ & $0.493(0.065)$ & $0.095(-0.103 ; 0.293)$ \\
\hline & 6 months & $0.362(0.073)$ & $0.598(0.093)$ & $0.236(0.005 ; 0.467)$ \\
\hline & I year & $0.386(0.089)$ & $0.64 I(0.118)$ & $0.255(-0.035 ; 0.545)$ \\
\hline BCVA (logMAR) & Pre & $0.548(0.075)$ & $0.457(0.07 \mid)$ & $-0.091(-0.301 ; 0.119)$ \\
\hline \multirow[t]{2}{*}{ adjusted for OCT MT } & 6 months & $0.415^{\mathrm{a}}(0.044)$ & $0.433(0.059)$ & $0.019(-0.132 ; 0.169)$ \\
\hline & I year & $0.419(0.054)$ & $0.483(0.072)$ & $0.064(-0.116 ; 0.245)$ \\
\hline \multirow[t]{5}{*}{ VF_MD } & Pre & $-6.29(0.39)$ & $-6.58(0.73)$ & $-0.29(-1.92 ; 1.33)$ \\
\hline & I month & $-7.2 \mathrm{I}^{\mathrm{a}}(0.54)$ & $-8.75^{\mathrm{a}}(0.8 \mathrm{I})$ & $-1.54(-3.45 ; 0.37)$ \\
\hline & 3 months & $-7.10(0.66)$ & $-8.83^{\mathrm{a}}(1.17)$ & $-1.73(-4.36 ; 0.90)$ \\
\hline & 6 months & $-7.88^{\mathrm{a}}(0.56)$ & $-8.96^{\mathrm{a}}(1.16)$ & $-1.08(-3.60 ; 1.45)$ \\
\hline & I year & $-8.70^{\mathrm{a}}(1.08)$ & $-10.06^{\mathrm{a}, \mathrm{b}}(1.46)$ & $-1.36(-4.97 ; 2.20)$ \\
\hline \multirow[t]{2}{*}{ ERG_b } & Pre & $347.66(30.33)$ & $340.8 \mathrm{I}(26.64)$ & $-6.85(-85.95 ; 72.26)$ \\
\hline & 6 months & $244.32^{\mathrm{a}}(19.42)$ & $205.65^{\mathrm{a}}(24.22)$ & $-38.67(99.50 ; 22.17)$ \\
\hline \multirow[t]{2}{*}{ ERG_b/a } & Pre & $3.01(0.30)$ & $2.90(0.28)$ & $-0.12(-0.93 ; 0.70)$ \\
\hline & 6 months & $3.16(0.27)$ & $2.96(0.22)$ & $-0.20(-0.89 ; 0.49)$ \\
\hline \multirow[t]{2}{*}{ ERG_OP } & Pre & $78.65(9.8 \mathrm{I})$ & $55.58(10.28)$ & $-23.07(-50.92 ; 4.78)$ \\
\hline & 6 months & $42.24^{a}(7.65)$ & $29.79^{a}(4.94)$ & $-12.44(-30.29 ; 5.41)$ \\
\hline \multicolumn{5}{|c|}{ Anatomic parameters } \\
\hline \multirow[t]{5}{*}{ OCT_SUP } & Pre & I $42.35(8.66)$ & I39.04 (8.94) & -3.31 (-27.7I; 21.09) \\
\hline & I month & $142.22(8.35)$ & I $39.27(6.40)$ & $-2.95(-23.58 ; 17.67)$ \\
\hline & 3 months & $136.78(5.78)$ & I 40.39 (7.07) & $3.6 I(-14.30 ; 21.5 I)$ \\
\hline & 6 months & I $35.33(5.85)$ & I34.33 (6.94) & $-0.99(-18.78 ; 16.79)$ \\
\hline & I year & | 40.90 (|4.59) & I $30.56(5.83)$ & $-10.35(-41.14 ; 20.45)$ \\
\hline \multirow[t]{5}{*}{ OCT_INF } & Pre & | 42.44 (4.78) & I 43.98 (4.62) & 1.54 (-II.49; 14.57) \\
\hline & I month & | 45.44 (4.89) & $|4| .86(6.08)$ & $-3.58(18.86 ; \mid 11.71)$ \\
\hline & 3 months & | 44.65 (5.48) & | 39.66 (5.0|) & $-5.00(-19.55 ; 9.55)$ \\
\hline & 6 months & $146.13(5.58)$ & $|40.2|(5.19)$ & $-5.92(-20.85 ; 9.02)$ \\
\hline & I year & $142.28(7.74)$ & $|32.0|^{a, b}(6.30)$ & $-10.27(-29.82 ; 9.28)$ \\
\hline \multirow[t]{5}{*}{ OCT_AVT } & Pre & I I 4.97 (5.35) & I 19.84 (5.82) & $4.87(-10.63 ; 20.38)$ \\
\hline & I month & I I 8.09 (5.07) & I I 7.97 (4.80) & $-0.11(-13.80 ; 13.57)$ \\
\hline & 3 months & II 5.79 (4.46) & II7.0| (5.15) & $1.22(-12.13 ; 14.58)$ \\
\hline & 6 months & II $5.1 \mid(5.05)$ & II $4.09(5.12)$ & $-1.02(-15.11 ; 13.07)$ \\
\hline & I year & I I $2.98(7.80)$ & $110.07^{a}(5.09)$ & $-2.90(-21.16 ; 15.35)$ \\
\hline \multirow[t]{5}{*}{ OCT_MT } & Pre & $227.85(21.17)$ & $358.68(19.27)$ & | $30.83(74.73 ; 186.93)$ \\
\hline & I month & $280.26^{\mathrm{a}}(35.03)$ & $387.26(33.66)$ & 106.41 (II.20; 20I.63) \\
\hline & 3 months & $272.63^{\mathrm{a}}(29.87)$ & 384.69 (36.69) & II $2.06(19.33 ; 204.79)$ \\
\hline & 6 months & $294.08^{\mathrm{a}}(29.13)$ & $391.32(32.34)$ & 97.24 (II.93; 182.55) \\
\hline & I year & $306.88^{\mathrm{a}}(27.24)$ & $390.98(32.28)$ & $84.11(1.31 ; 166.90)$ \\
\hline
\end{tabular}

Notes: Statistical comparisons within group: a $\mathrm{P}<0.05$ when compared with pretreatment; ${ }^{\mathrm{b}} \mathrm{P}<0.05$ when compared with 6 months; data presented as means (standard errors). Abbreviations: GA group, treated with glatiramer acetate; BCVA, best corrected visual acuity; Cl, confidence interval; VF_MD, visual field _ mean deviation; OCT_SUP, OCT_INF, OCT_AVT, OCT_MT: optical coherence tomography superior, inferior, average thickness, macular thickness; ERG_b, ERG_b/a, ERG_OP: electroretinography b wave, b/a wave, oscillatory potential.

used by Shulman et al to study neuroprotection with PN-277, another synthetic peptide capable of boosting the immune system and enhancing neurotrophic factor secretion. ${ }^{26}$ Both drugs demonstrated an ameliorative effect in neural tissue such as the retina. In humans, Landa et al found that GA reduced the drusen area in dry age-related macular disease. ${ }^{27}$ The main protein present in drusen is beta-amyloid, which is also present in Alzheimer's disease (AD) plaques. Recent evidence showed that $T$ cell-based vaccination with GA in $\mathrm{AD}$ mice model resulted in modulation of microglia into a neuroprotective phenotype. As a result, reduction of cognitive decline, elimination of plaque formation, and induction of neuronal survival and neurogenesis was observed. ${ }^{15}$ This type of immunization may be of clinical significance in reducing laser-induced retinal injuries in humans.

In our study, the comparison between pre- and postPRP in the same group showed a statistically significant worsening in the placebo group, as demonstrated by thinning of inferior RFNL and average thickness (measured by OCT), which did not occur in the group treated 

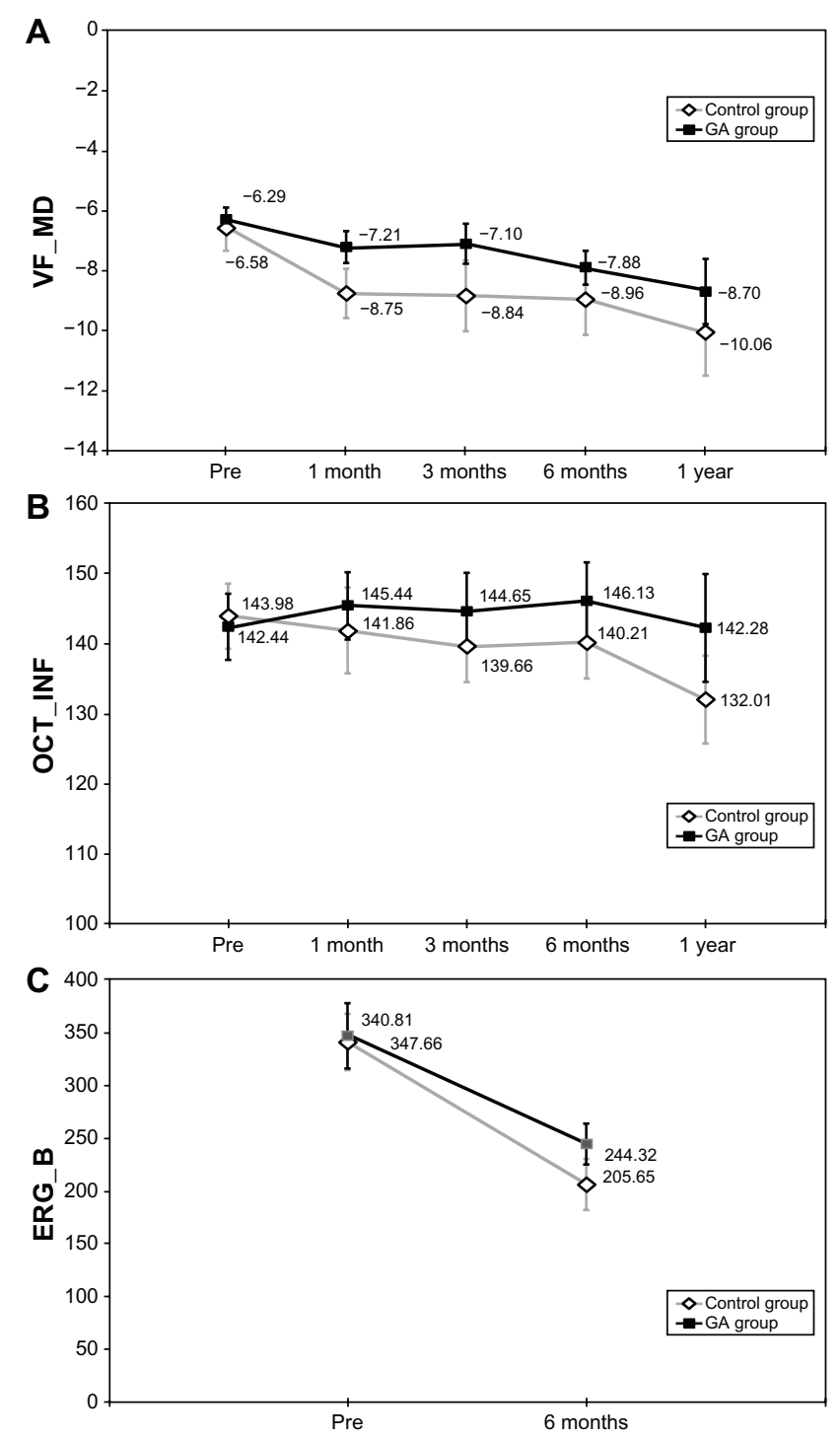

Figure 2 Functional and anatomical examinations at baseline and follow-up. Note: Data are presented as means \pm standard error of the mean.

Abbreviations: GA group, treated with glatiramer acetate; (A) VF_MD, visual field mean deviation; (B) OCT_INF, inferior retinal thickness in optical coherence tomography; (C) ERG_B, electroretinography B wave.

with glatiramer acetate. Lim et al found thinner RNFL measurements in the inferior and nasal peripapillary regions in diabetic patients with PRP compared with both diabetic patients without PRP and normal eyes. ${ }^{17} \mathrm{Kim}$ and Cho also observed reduction in RNFL (average thickness) 6 months post-PRP in the analysis within groups..$^{28}$ Finally, Muqit et al initially found increased thickness in the group treated 10 weeks post-laser, and thickness reduction 6 months after treatment. ${ }^{29}$

Our data also revealed less NFL atrophy, less VFMD worsening and less B-wave reduction in the treatment group as compared with the controls, but the difference was not significant, possibly because of the wide variability in the sample and follow-up problems that led to a smaller sample and loss of test power. Visual acuity was better in the GA group at 6 months after treatment, but the difference was not sustained when the analysis was performed with macular thickness as a covariable. Macular thickness was significantly different between groups; macular thickness was higher in the control group in all examinations.

Importantly, GA was given weekly in this study; in contrast to its daily administration in patients suffering from relapsing-remitting multiple sclerosis. ${ }^{14}$ The daily administration of GA in an animal model of glaucoma was ineffective. ${ }^{13}$

Our study was limited to 47 eyes, largely because the number of patients with severe nonproliferative diabetic retinopathy or proliferative diabetic retinopathy with no previous treatment and good vision was limited. Another limitation was the worsening of diabetic retinopathy throughout the study due to inappropriate systemic control. ${ }^{30}$ In the present study, we had some complications, such as the worsening of macular edema, tractional retinal detachment, vitreous hemorrhage and others, that impaired the comparative anatomical and functional evaluation for some patients. Despite the limitations described above, the current study was conducted using rigorous scientific methodology and provides encouraging pilot data that justify a large, multicenter, randomized clinical trial to confirm the efficacy of GA.

\section{Conclusion}

The results of this study suggest that weekly GA treatment has a potential neuroprotective effect on the RNFL following photocoagulation for diabetic retinopathy.

\section{Disclosure}

None of the authors had any competing financial interests that might create a conflict of interest in connection with this manuscript.

\section{References}

1. Singh R, Ramasamy K, Abraham C, Gupta V, Gupta A. Diabetic retinopathy: an update. Indian J Ophthalmol. 2008;56(3):178-188.

2. Photocoagulation treatment of proliferative diabetic retinopathy. Clinical application of Diabetic Retinopathy Study (DRS) findings, DRS Report Number 8. The Diabetic Retinopathy Study Research Group. Ophthalmology. 1981;88(7):583-600.

3. Early Treatment Diabetic Retinopathy Study design and baseline patient characteristics. ETDRS report number 7. Ophthalmology. 1991; 98(Suppl 5):741-756.

4. Early photocoagulation for diabetic retinopathy. ETDRS report number 9. Early Treatment Diabetic Retinopathy Study Research Group. Ophthalmology. 1991;98(Suppl 5):766-785. 
5. Photocoagulation for diabetic macular edema. Early Treatment Diabetic Retinopathy Study report number 1. Early Treatment Diabetic Retinopathy Study research group. Arch Ophthalmol. 1985;103(12): 1796-1806.

6. Ben-Shlomo G, Belokopytov M, Rosner M, et al. Functional deficits resulting from laser-induced damage in the rat retina. Lasers Surg Med. 2006;38(7):689-694.

7. Dastgheib K, Bressler SB, Green WR. Clinicopathologic correlation of laser lesion expansion after treatment of choroidal neovascularization. Retina. 1993;13(4):345-352.

8. Brancato R, Pece A, Avanza P, Radrizzani E. Photocoagulation scar expansion after laser therapy for choroidal neovascularization in degenerative myopia. Retina. 1990;10(4):239-243.

9. Osborne NN, Chidlow G, Wood JP, Schmidt KG, Casson R, Melena J. Expectations in the treatment of retinal diseases: neuroprotection. Curr Eye Res. 2001;22(5):321-332.

10. Barkana Y, Belkin M. Neuroprotection in ophthalmology: a review. Brain Res Bull. 2004;62(6):447-453.

11. Schori H, Kipnis J, Yoles E, et al. Vaccination for protection of retinal ganglion cells against death from glutamate cytotoxicity and ocular hypertension: implications for glaucoma. Proc Natl Acad Sci US A. 2001;98(6):3398-3403.

12. Kipnis J, Yoles E, Porat Z, et al. T cell immunity to copolymer 1 confers neuroprotection on the damaged optic nerve: possible therapy for optic neuropathies. Proc Natl Acad Sci U S A. 2000;97(13):7446-7451.

13. Bakalash S, Shlomo GB, Aloni E, et al. T-cell-based vaccination for morphological and functional neuroprotection in a rat model of chronically elevated intraocular pressure. J Mol Med. 2005;83(11):904-916.

14. Kipnis J, Schwartz M. Dual action of glatiramer acetate (Cop-1) in the treatment of CNS autoimmune and neurodegenerative disorders. Trends Mol Med. 2002;8(7):319-323.

15. Butovsky O, Koronyo-Hamaoui M, Kunis G, et al. Glatiramer acetate fights against Alzheimer's disease by inducing dendritic-like microglia expressing insulin-like growth factor 1. Proc Natl Acad Sci USA 2006;103(31):11784-11789.

16. Altman DG, Schulz KF, Moher D, et al. The revised CONSORT statement for reporting randomized trials: explanation and elaboration. Ann Intern Med. 2001;134(8):663-694.

17. Lim MC, Tanimoto SA, Furlani BA, et al. Effect of diabetic retinopathy and panretinal photocoagulation on retinal nerve fiber layer and optic nerve appearance. Arch Ophthalmol. 2009;127(7):857-862.
18. Zeger SL, Liang KY. Longitudinal data analysis for discrete and continuous outcomes. Biometrics. 1986;42(1):121-130.

19. MurdochIE, Morris SS, Cousens SN. People and eyes: statistical approaches in ophthalmology. Br J Ophthalmol. 1998;82(8):971-973.

20. Moalem G, Leibowitz-Amit R, Yoles E, Mor F, Cohen IR, Schwartz M. Autoimmune $\mathrm{T}$ cells protect neurons from secondary degeneration after central nervous system axotomy. Nat Med. 1999;5(1):49-55.

21. Yoles E, Hauben E, Palgi O, et al. Protective autoimmunity is a physiological response to CNS trauma. J Neurosci. 2001;21(11):3740-3748.

22. Hauben E, Butovsky O, Nevo U, et al. Passive or active immunization with myelin basic protein promotes recovery from spinal cord contusion. J Neurosci. 2000;20(17):6421-6430.

23. Kerschensteiner M, Gallmeier E, Behrens L, et al. Activated human $\mathrm{T}$ cells, B cells, and monocytes produce brain-derived neurotrophic factor in vitro and in inflammatory brain lesions: a neuroprotective role of inflammation? J Exp Med. 1999;189(5):865-870.

24. Shechter R, London A, Varol C, et al. Infiltrating blood-derived macrophages are vital cells playing an anti-inflammatory role in recovery from spinal cord injury in mice. PLoS Med. 2009;6(7):e1000113.

25. Belokopytov M, Ben-Shlomo G, Rosner M, et al. Functional efficacy of glatiramer acetate treatment for laser-induced retinal damage in rats. Lasers Surg Med. 2008;40(3):196-201.

26. Shulman S, Belokopytov M, Dubinsky G, Belkin M, Rosner M. Ameliorative effect of PN-277 on laser-induced retinal damage. Graefes Arch Clin Exp Ophthalmol. 2009 Mar;247(3):343-348.

27. Landa G, Butovsky O, Shoshani J, Schwartz M, Pollack A. Weekly vaccination with Copaxone (glatiramer acetate) as a potential therapy for dry age-related macular degeneration. Curr Eye Res. 2008;33(11): 1011-1013.

28. Kim HY, Cho HK. Peripapillary retinal nerve fiber layer thickness change after panretinal photocoagulation in patients with diabetic retinopathy. Korean J Ophthalmol. 2009 Mar;23(1):23-26.

29. Muqit MM, Wakely L, Stanga PE, Henson DB, Ghanchi FD. Effects of conventional argon panretinal laser photocoagulation on retinal nerve fibre layer and driving visual fields in diabetic retinopathy. Eye (Lond). 2010;24(7):1136-1142.

30. Davis MD, Fisher MR, Gangnon RE, et al. Risk factors for high-risk proliferative diabetic retinopathy and severe visual loss: Early Treatment Diabetic Retinopathy Study Report \#18. Invest Ophthalmol Vis Sci. 1998;39(2):233-252.
Clinical Ophthalmology

\section{Publish your work in this journal}

Clinical Ophthalmology is an international, peer-reviewed journal covering all subspecialties within ophthalmology. Key topics include: Optometry; Visual science; Pharmacology and drug therapy in eye diseases; Basic Sciences; Primary and Secondary eye care; Patient Safety and Quality of Care Improvements. This journal is indexed on

\section{Dovepress}

PubMed Central and CAS, and is the official journal of The Society of Clinical Ophthalmology (SCO). The manuscript management system is completely online and includes a very quick and fair peer-review system, which is all easy to use. Visit http://www.dovepress.com/ testimonials.php to read real quotes from published authors. 